Research paper

\title{
Micellar promoted alkenes isomerization in water mediated by a cationic half-sandwich $\mathrm{Ru}(\mathrm{II})$ complex
}

\author{
Laura Sperni, Alessandro Scarso, Giorgio Strukul* \\ Dipartimento di Scienze Molecolari e Nanosistemi, Università Ca' Foscari di Venezia, via Torino 155, 30172 Mestre Venezia, Italy
}

\section{A R T I C L E I N F O}

\section{Article history:}

Received 15 April 2016

Received in revised form 30 May 2016

Accepted 3 June 2016

Available online 4 June 2016

GS dedicates this work to the late Professor

Rino A. Michelin, companion of many

chemical adventures and friend of a

lifetime.

\section{Keywords:}

Allylbenzenes

Isomerization

Ruthenium

Micellar media

Surfactants

\begin{abstract}
A B S T R A C T
Micellar media in water provide a simple and efficient environment to favor the double bond isomerization of terminal alkenes catalyzed by the cationic half-sandwich complex $\mathbf{1}$ at $95^{\circ} \mathrm{C}$. The micellar medium favors both catalyst dissolution in water by means of ion-pairing with the preferred anionic surfactants as well as substrate dissolution thus favoring its conversion into products.
\end{abstract}

(c) 2016 Elsevier B.V. All rights reserved.

\section{Introduction}

Recently the stringent constraints required by the environmental legislation in many countries are imposing to industry new paradigms and methods pushing towards drastic modifications in the way in which fine chemicals and pharmaceuticals are produced. We are currently living in a new era where industrial synthesis must comply with the implementation of sustainability criteria [1] based on the almost 20 year old twelve principles of green chemistry [2]. Among others, the use of catalytic rather than stoichiometric methods and the avoidance of organic solvents or their replacement with less hazardous media are often the first steps to convert an old synthetic method into a more sustainable one. In an industrial chemical production the choice of the solvent is not trivial [3] because about half of the total amount of waste is constituted by the solvent [4,5] and, quite commonly, the simplest way to dispose it is eventually incineration to recover heat. Chlorinated, aromatic and highly polar solvents like DMF and DMSO are usually considered for use only if no alternatives are possible. Water, as the most abundant liquid on earth, is the only one that,

\footnotetext{
* Corresponding author.

E-mail address: strukul@unive.it (G. Strukul).
}

together with low cost and high safety, provides almost negligible impact for the environment. The latter aspect is clearly demonstrated by the fact that its E-factor value is considered equal to zero [4]. In all recent solvent selection guides [6] developed by different chemical and pharmaceutical companies, water is always considered as highly desirable [7]. Recent studies emphasized also that reactions in water can benefit from extra features like enhanced selectivity (chemo-, regio-, stereo- and enantio-) if compared to the use of organic media for the same process [8]. Because of its many advantages [9], water is witnessing a sort of renaissance as an alternative reaction medium [10]. The peculiarity of water is often related to the hydrophobic effect that is responsible for most of the increased selectivities performed by reactants both when dissolved in water and under "on water" conditions [11]. On the other hand, the same properties cause also some challenging drawbacks, in primis the generally low solubility of organic substrates and of most metal complex catalysts that in some cases are also inactivated/decomposed by this medium. In order to overcome such limitations, traditional catalysts are modified making use of water soluble ligands bearing polar and/or charged tags [12] to increase their solubility.

A simpler and more straightforward approach consists in the use of surfactants whose role is to cope with reagents and 
catalysts. The addition of surfactants to water leads to the spontaneous formation (self-assembly) of micelles as supramolecular aggregates that, thanks to their apolar core and polar surface, are able to dissolve apolar substrates and catalysts in their core but also ionic catalysts close to the surface. Micellar catalysis $[8 \mathrm{e}, 13,14]$ has been an alternative approach to traditional catalysis in organic media for years, but because of the recent, more stringent environmental concerns, it is becoming a real alternative gaining pace also in drug productions [15]. Several are in fact the examples of reactions that benefit from the use of micellar media vs. organic media on grounds such as reaction rate, selectivity at all levels, ease of product isolation and recyclability [16].

Micellar catalysis is particularly suited for reactions where soft Lewis acidic metal catalysts interact with soft Lewis basic substrates, in particular reactions involving late transition metals and unsaturated substrates are usually unaffected by the presence of water or by the nature of the surfactant. In this field our research group has obtained very good results using micellar catalysis in water in e.g. alkyne hydration [17] or alkene hydroformylation [18] and epoxidation [14b], or sulfoxidation [14c], mediated by cationic Pt(II) catalysts using economic, traditional, commercially available anionic surfactants like e.g. sodium dodecyl sulfate, observing in some cases possible catalyst recycling.

Half-sandwich complexes of ruthenium bearing aryl or cyclopentadienyl ligands turned out to be interesting catalysts for a series of reactions. Examples span from the allylic substitution reaction [19], to the Diels-Alder cycloaddition reaction with high selectivity towards the exo product [20], to the $[2+2+2]$ cyclotrimerization of alkynes leading to aromatic compounds [21] and to the cyclopropanation of alkenes with diazoacetate carbene precursors with good selectivity for the formation of the cis isomer [22], just to name a few. As long as intramolecular reactions are concerned, the Ru-catalyzed isomerization of alkenes has been known for decades [23] including some recent examples based on monocationic $\mathrm{Ru}(\mathrm{II})$ species bearing 1-phenyl-indenyl and chloride anionic ligands [24].

Recently we successfully investigated the nitrile hydration reaction to amides in micellar media catalyzed by neutral half-sandwich $\mathrm{Ru}(\mathrm{II})$ complexes bearing cymene, phosphite and chlorine ligands [25]. Spurred by these positive results related to a good solubilization of both catalyst and substrate in water, we became interested with the double bond migration in terminal alkenes to give the corresponding internal isomers. The reaction has some interesting industrial applications like e.g. the estragole, eugenol, and safrole isomerization into the corresponding internal alkenes [26] used as fragrances, and can be carried out with both homogeneous and heterogeneous catalysts [27].

Herein we report an alternative supramolecular approach to this reaction utilizing readily available and cheap surfactants to promote the terminal alkene isomerization reaction in the presence of 1 (Scheme 1). To the best of our knowledge the use of micellar environments has never been investigated for this reaction.

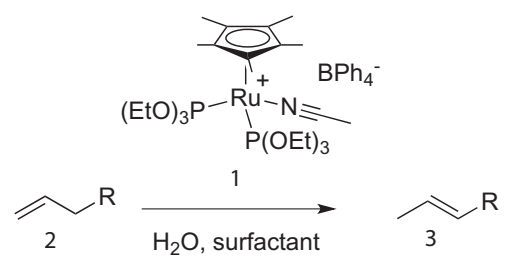

Scheme 1. Alkene isomerization reaction mediated by the half-sandwich $\mathrm{Ru}(\mathrm{II})$ complex $\mathbf{1}$ in water under micellar conditions.

\section{Experimental}

\subsection{General}

${ }^{1} \mathrm{H}$ NMR were recorded at $298 \mathrm{~K}$, on a Bruker AVANCE 300 spectrometer operating at $300.15 \mathrm{MHz}$. $\delta$ values in ppm are relative to $\mathrm{SiMe}_{4}$. GC analyses were performed on HP Series II 5890 instrument equipped with a 30 m HP5 capillary column, using He as gas carrier and FID. GC-MS analyses were performed on a GC Trace GC 2000 instrument equipped with a 30 m HP5-MS capillary column using He gas carrier and coupled with a MS Thermo Finnigan Trace MS quadrupole with Full Scan method.

Solvents and reactants were used as received; otherwise they were purified according to literature methods [28]. TLC analysis were performed on TLC Polygram ${ }^{\circledR}$ Sil G/UV254 of 0.25 mm thickness and flash-chromatography separations were performed on silica gel Merck 60, 230-400 mesh [29].

\subsection{Synthesis of $\left[\mathrm{Ru}\left(\eta^{5}-\mathrm{C}_{5} \mathrm{Me}_{5}\right)\left(\mathrm{CH}_{3} \mathrm{CN}\right)\left\{\mathrm{P}(\mathrm{OEt})_{3}\right\}_{2}\right] B P h_{4} \mathbf{1}$}

$\left[\mathbf{R u}\left(\eta^{5}-\mathbf{C}_{5} \mathbf{M e}_{5}\right)\left(\mathbf{C H}_{3} \mathbf{C N}\right)\left\{\mathbf{P}(\mathbf{O E t})_{3}\right\}_{2}\right] \mathbf{B P h}_{4}$ 1. An excess of $\mathrm{P}(\mathrm{OEt})_{3}$ (6.6 mmol, $1.1 \mathrm{~mL}$ ) was added to a solution of the chloro-compound $\operatorname{RuCl}\left(\eta^{5}-\mathrm{C}_{5} \mathrm{Me}_{5}\right)\left(\mathrm{PPh}_{3}\right)_{2} 4(220 \mathrm{mg}, 0.3 \mathrm{mmol})$ in $10 \mathrm{~mL}$ toluene, and the solution was stirred for $2 \mathrm{~h}$. The solvent and the excess phosphite were removed under reduced pressure to give an oil, which was dissolved in ethanol $(8 \mathrm{~mL})$. An excess of acetonitrile $(6 \mathrm{mmol}, 0.32 \mathrm{~mL})$ and an excess of $\mathrm{NaBPh}_{4}(0.6 \mathrm{mmol}$, $205 \mathrm{mg}$ ) in ethanol $(2 \mathrm{~mL})$ were added and the reaction mixture stirred for $24 \mathrm{~h}$. The pale-yellow solid which separated was filtered and crystallized from dichloromethane and ethanol; yield $\geqslant 65 \%$.

${ }^{1} \mathrm{H}$ NMR $\left(\mathrm{CD}_{2} \mathrm{Cl}_{2}, 20{ }^{\circ} \mathrm{C}\right) \delta: 7.65-6.87(\mathrm{~m}, 20 \mathrm{H}, \mathrm{Ph}), 3.95(\mathrm{~m}, 12 \mathrm{H}$, $\left.\mathrm{CH}_{2}\right), 1.69\left(\mathrm{t}, 3 \mathrm{H}, \mathrm{CH}_{3} \mathrm{CN}\right), 1.31\left(\mathrm{~s}, 15 \mathrm{H}, \mathrm{CH}_{3} \mathrm{C}_{5} \mathrm{Me}_{5}\right), 1.29(\mathrm{t}, 18 \mathrm{H}$, $\mathrm{CH}_{3}$ phos); ${ }^{31} \mathrm{P}\left\{{ }^{1} \mathrm{H}\right\}$ NMR $\left(\mathrm{CD}_{2} \mathrm{Cl}_{2}, 20{ }^{\circ} \mathrm{C}\right) \delta$ : 145.3 (s); Anal. Calcd for $\mathrm{C}_{48} \mathrm{H}_{68} \mathrm{BNO}_{6} \mathrm{P}_{2} \mathrm{Ru}$ (928.89): C, 62.07; $\mathrm{H}, 7.38$; N, 1.51; Found: C, $61.89 ; \mathrm{H}, 7.44 ; \mathrm{N}, 1.43 \%$.

\subsection{Catalytic procedure}

In a $3 \mathrm{~mL}$ vial were introduced the surfactant followed by water $(1 \mathrm{~mL})$. The mixture was stirred until complete dissolution and formation of a clear solution. To this, catalyst $1(0.005 \mathrm{mmol})$ was added and the mixture was stirred for $10 \mathrm{~min}$, followed by allylbenzene ( 50 eq. with respect to $\mathbf{1}$ ). The mixture was heated at $95{ }^{\circ} \mathrm{C}$ under stirring at $750 \mathrm{rpm}$. After $18 \mathrm{~h}$ the aqueous reaction mixture was extracted two times with ethyl acetate and the organic phase was analyzed by GC and GC-MS. The structure of the isomerized products were confirmed by GC-MS and ${ }^{1} \mathrm{H}$ NMR.

\section{Results and discussion}

\subsection{Synthesis and characterization of $\mathbf{1}$}

With the aim of developing a simple small cationic half-sandwich complex reminiscent of those already known to operate in the alkene isomerization reaction but focusing on an easy solubilization in water in the presence of micellar aggregates, we designed complex $\mathbf{1}$ as a good synthetic target bearing the pentamethylcyclopentadienyl ligand, two phosphite neutral ligands and one neutral labile acetonitrile ligand that could be easily displaced by the incoming alkene substrate but not by water molecules.

The synthesis of complex 1 was achieved in overall two synthetic steps starting from $\mathrm{RuCl}_{3} \cdot 3\left(\mathrm{H}_{2} \mathrm{O}\right)$ in a one pot reaction. Initially, complex $\operatorname{RuCl}\left(\eta^{5}-\mathrm{C}_{5} \mathrm{Me}_{5}\right)\left(\mathrm{PPh}_{3}\right)_{2} 4$ was prepared following the method reported in the literature from $\mathrm{RuCl}_{3} \cdot 3\left(\mathrm{H}_{2} \mathrm{O}\right)$ by reac- 
tion with pentamethylcyclopentadienyl ligand $\left(\mathrm{Cp}^{*}\right)$ leading to $\left[\left(\eta^{5}-\mathrm{C}_{5} \mathrm{Me}_{5}\right) \mathrm{RuCl}\right]_{4}$ that was further reacted with triphenylphosphine [30]. The obtained intermediate species 4 was not isolated but directly reacted with an excess of triethylphosphite (Scheme 2) in order to lead to the displacement of the two molecules of triphenylphosphine. By addition of sodium tetraphenylborate in the presence of an excess of acetonitrile the halogen ligand was removed and substituted with the neutral acetonitrile, making the overall complex $\mathbf{1}$ cationic in the presence of the weakly coordinating tetraphenylborate counteranion (Scheme 2). The last step enabled to completely substitute all ligands except the $\mathrm{Cp}^{*}$ without requiring isolation of the intermediate species.

The synthesized complex, dissolved in chloroform-d, showed in the ${ }^{1} \mathrm{H}$ NMR spectrum aromatic resonances typical of the tetraphenylborate anion, the presence of the methyl substituents of the $\mathrm{Cp}^{*}$ at $1.31 \mathrm{ppm}$, the ethyl moieties of the phosphite ligands at 3.95 and $1.31 \mathrm{ppm}$ and the presence of the coordinated acetonitrile as confirmed by the existence of a singlet resonance at $1.69 \mathrm{ppm}$ (Fig. 1B). As long as the ${ }^{31} \mathrm{P}$ NMR spectrum is concerned, a singlet resonance was observed at $145.3 \mathrm{ppm}$ indicating the symmetry of the molecule (Fig. 1D). Some resonances were observed also when changing the medium from an organic chlorinated solvent to $\mathrm{D}_{2} \mathrm{O}$ in the presence of sodium dodecyl sulfate (SDS) as a typical anionic surfactant able to solubilize cationic complexes (Fig. 1A and C). In fact, as clearly observed in the ${ }^{1} \mathrm{H}$ spectrum reported in Fig. 1A, all the aromatic resonances of the anion of the complex are clearly present in the spectrum in deuterated water, while the resonances of the cationic part of the complex are covered by the resonances of the surfactant. On the other hand, the ${ }^{31}$ P NMR spectrum clearly shows the singlet at $144.7 \mathrm{ppm}$ confirming the presence of the transition metal complex in the micelle (Fig. 1C). No NMR signals are observed in pure water as the catalyst is not soluble.

Attempts were made to investigate the positioning of the catalyst with respect to the micellar aggregates using 2D NMR NOESY and DOSY experiments. No useful information was obtained due to the overlap of the resonances of the cationic part of the metal catalyst and those of the surfactant. However, the cationic nature of the complex and the anionic nature of the surfactant seem to suggest that the catalyst is likely located close to the external surface of the micelle, as has already been observed with other cationic phosphine containing noble metal complexes [14c].

\subsection{Catalytic studies}

The isomerization of allyl benzene derivatives such as estragole, eugenol, and safrole to the corresponding internal alkenes used as fragrances are all important industrial processes, seeking for both high productivity and high selectivity for the $\mathrm{E}$ isomer. In our investigation, we initially carried out as test reaction the isomerization of allylbenzene in the presence of $2 \mathrm{~mol} \%$ of catalyst 1 in

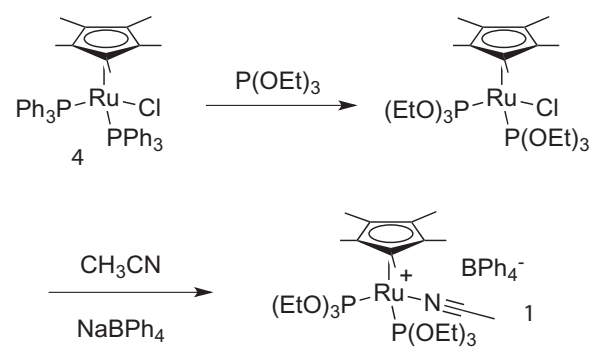

Scheme 2. One pot direct synthesis of the final catalytically active complex $\mathbf{1}$ from complex 4 by substitution of the phosphine ligand with an excess of triethylphosphite and subsequent in situ replacement of the chloride ligand with acetonitrile.
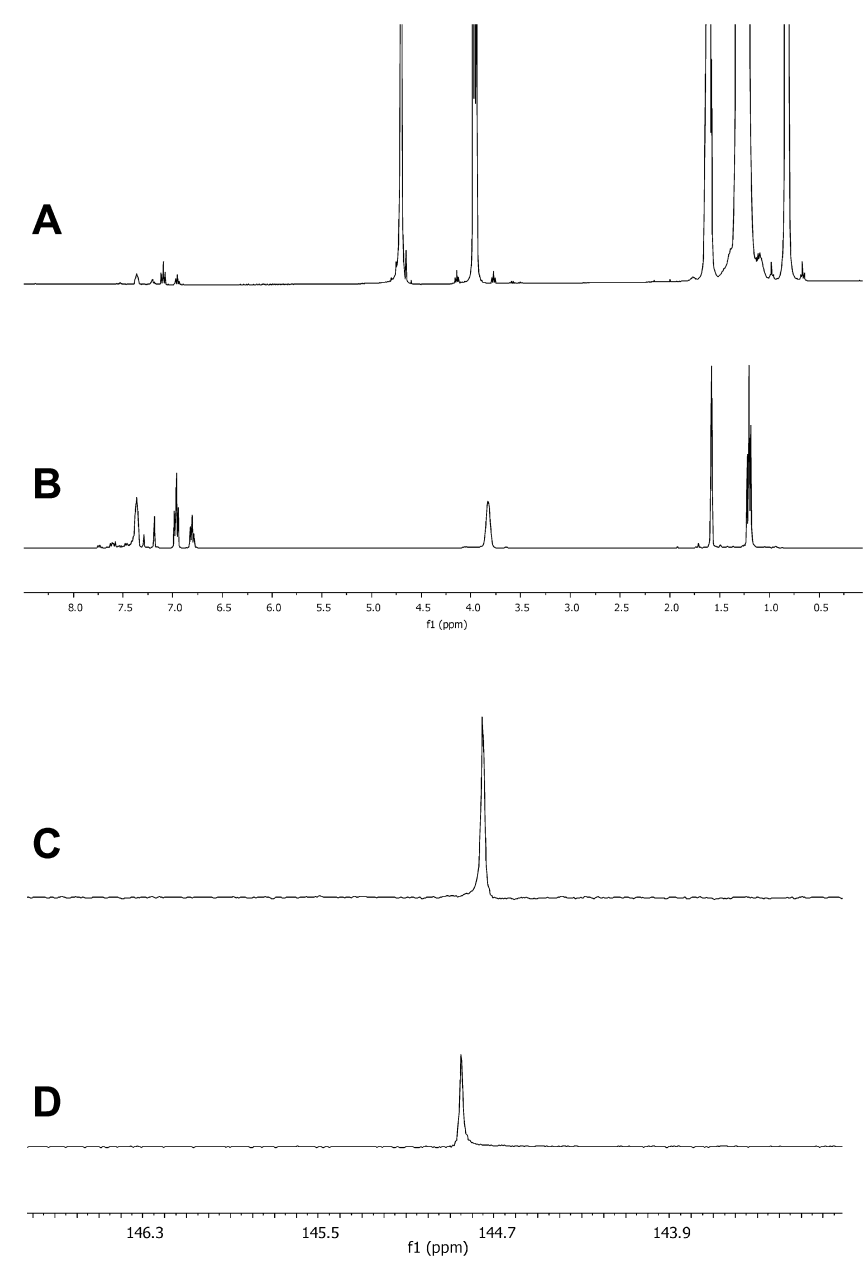

Fig. 1. A) ${ }^{1} \mathrm{H}$ NMR spectrum of the $\mathrm{Ru}(\mathrm{II})$ complex $1,4 \mathrm{mM}$ in $\mathrm{D}_{2} \mathrm{O}$ in the presence of SDS $50 \mathrm{mM}$; B) ${ }^{1} \mathrm{H}$ NMR spectrum of the Ru(II) complex 1, $4 \mathrm{mM}$ in chloroform-d; C) ${ }^{31} \mathrm{P}$ NMR spectrum of the $\mathrm{Ru}(\mathrm{II})$ complex $1,4 \mathrm{mM}$ in $\mathrm{D}_{2} \mathrm{O}$ in the presence of SDS $50 \mathrm{mM}$; D) ${ }^{31} \mathrm{P}$ NMR spectrum of the Ru(II) complex 1, $4 \mathrm{mM}$ in chloroform-d.

different media ranging from organic solvents to water with the addition of a wide range of possible surfactants [31] (Table 1) seeking for the best medium to dissolve all species and favor the isomerization reaction.

The isomerization to $\alpha$-methylstyrene was initially investigated in organic media observing that while toluene was not a good sol-

Table 1

Allylbenzene isomerization mediated by $\mathrm{Ru}(\mathrm{II})$ catalyst $\mathbf{1}$ in different media.

\begin{tabular}{lll}
\hline$\#$ & Reaction medium & $\begin{array}{l}\text { Yield } \\
(\%)^{\mathrm{a}}\end{array}$ \\
\hline 1 & Toluene & $<2$ \\
2 & 1,2 -dichloroethane (DCE) & 49 \\
3 & $\mathrm{H}_{2} \mathrm{O}$ & $<2$ \\
4 & $\mathrm{H}_{2} \mathrm{O} /$ cetyl trimenthylammonium bromide (CTAB) & $<2$ \\
5 & $\mathrm{H}_{2} \mathrm{O} / N$-dodecyl- $N$, -dimethyl-3-amonium-1-propan & 5 \\
& sulfonate (DDAPS) & 12 \\
6 & $\mathrm{H}_{2} \mathrm{O}$ /Triton X-100 & 7 \\
7 & $\mathrm{H}_{2} \mathrm{O} /$ TPGS & 3 \\
8 & $\mathrm{H}_{2} \mathrm{O} /$ TPGS-750-M & 7 \\
9 & $\mathrm{H}_{2} \mathrm{O} /$ dioctyl solfosuccinate sodium salt (DOSS) & $<2$ \\
10 & $\mathrm{H}_{2} \mathrm{O} /$ sodium dodecylbenzenesulfonate (SDBS) & 20 \\
11 & $\mathrm{H}_{2} \mathrm{O} /$ sodium dodecylsulfate (SDS) & 21 \\
12 & $\mathrm{H}_{2} \mathrm{O} /$ sodium hexadecyl sulfonate (SHS) & \\
\hline
\end{tabular}

Experimental conditions: [allylbenzene] = $200 \mathrm{mM}$; [1] =4 mM (2 mol\%); [surfactant] $=50 \mathrm{mg}$, for TPGS-750-M $2 \mathrm{w} / \mathrm{w} \%$; water $1 \mathrm{~mL}, 95^{\circ} \mathrm{C}, 18 \mathrm{~h}$.

a Determined by extraction with ethyl acetate and GC analysis. 
vent leading to negligible yield for the internal alkene product, in chlorinated solvent the reaction was much more favored observing $49 \%$ yield (E:Z 98:2) after $18 \mathrm{~h}$ at $95^{\circ} \mathrm{C}$ (entries 1 and 2, Table 1 ).

The reaction in pure water did not proceed at all due to lack of solubility of both substrate and catalyst (entry 3, Table 1 ). A series of surfactants were then investigated, observing that neither cationic tensides like cetyl trimethylammonium bromide (CTAB), nor zwitterionic $N$-dodecyl- $N, N$-dimethyl-3-amonium-1-propan sulfonate (DDAPS, entry 5 , Table 1 ) favored the reaction with yields in all cases lower than $10 \%$. Among neutral surfactants, only Triton-X100 (entry 6, Table 1 ) led to a minimal product formation while $\mathrm{D}$ - $\alpha$-tocopherol polyethylene glycol 1000 succinate (TPGS) and DL- $\alpha$-tocopherol methoxypolyethylene glycol succinate (TPGS-750-M) turned out to be inefficient in solubilizing the Ru complex in water (entries 7 and 8, Table 1). As long as anionic surfactants are concerned, dioctyl sulfosuccinate (DOSS, entry 9, Table 1) and sodium dodecylbenzenesulfonate (SDBS, entry 10, Table 1) did not allow sufficient solubilization of the catalyst and consequently alkene isomerization. Conversely, two anionic surfactants, in particular sodium dodecyl sulfate (SDS, entry 11, Table 1) and sodium hexadecyl sulfonate (SHS, entry 12, Table 1) led both to catalyst solubilization and formation of the isomerized product in 20 and 21\% yield, respectively (E:Z 99:1 in both cases). Even in the latter case yields observed are not very high but comparable (even if lower) to DCE as solvent.

Even if defining the structure of the micellar medium at $95{ }^{\circ} \mathrm{C}$ may be uncertain, this result is undoubtedly due to a solubilization effect of catalyst $\mathbf{1}$ in the reaction medium, as demonstrated by Fig. 1 as opposed to pure water where the complex is completely insoluble. This point is further supported by the effect of surfactant concentration reported in Table 2 . We recall that a similar behavior by micellar media at high temperature was observed in the hydration of nitriles catalyzed by Ru complexes [25] and in the hydroformylation of terminal alkenes catalyzed by Pt complexes [18].

Transition metal catalyzed isomerization reactions generally proceed through two possible pathways (i) metal-hydride addition elimination to and from the coordinated substrate and (ii) olefin oxidative addition to produce hydridoallyl metal intermediates. Given the aprotic nature of the solvation sphere surrounding the catalyst (toluene, DCE, the hydrophobic part of the micelles) in the present case in-situ hydride formation seems quite unlikely. On this basis it seems reasonable to suggest that the isomerization reaction is likely to proceed via the second possible pathway with prior displacement of acetonitrile by the incoming allylbenzene substrate, as has been recently found by Nolan and coworkers for similar cyclopentadienyl Ru(II) complexes [32].

\section{Table 2}

Allylbenzene isomerization mediated by $\mathrm{Ru}(\mathrm{II})$ catalyst $\mathbf{1}$ : effect of the concentrations of SDS and SHS.

\begin{tabular}{llll}
\hline$\#$ & Medium & Surfactant concentration $(\mathrm{mM})$ & ${\text { Yield }(\%)^{\mathrm{a}}}^{\mathrm{a}}$ \\
\hline 1 & $\mathrm{H}_{2} \mathrm{O} / \mathrm{SDS}$ & 25 & 15 \\
2 & $\mathrm{H}_{2} \mathrm{O} / \mathrm{SDS}$ & 60 & 42 \\
3 & $\mathrm{H}_{2} \mathrm{O} / \mathrm{SDS}$ & 125 & 34 \\
4 & $\mathrm{H}_{2} \mathrm{O} / \mathrm{SDS}$ & 250 & 20 \\
5 & $\mathrm{H}_{2} \mathrm{O} / \mathrm{SDS}$ & 370 & 15 \\
6 & $\mathrm{H}_{2} \mathrm{O} / \mathrm{SDS}$ & 500 & 15 \\
7 & $\mathrm{H}_{2} \mathrm{O} / \mathrm{SHS}$ & 25 & 8 \\
8 & $\mathrm{H}_{2} \mathrm{O} / \mathrm{SHS}$ & 50 & 19 \\
9 & $\mathrm{H}_{2} \mathrm{O} / \mathrm{SHS}$ & 100 & 43 \\
10 & $\mathrm{H}_{2} \mathrm{O} / \mathrm{SHS}$ & 200 & 20 \\
11 & $\mathrm{H}_{2} \mathrm{O} / \mathrm{SHS}$ & 330 & 21 \\
12 & $\mathrm{H}_{2} \mathrm{O} / \mathrm{SHS}$ & 450 & 18 \\
\hline
\end{tabular}

Experimental conditions: [allylbenzene] = $200 \mathrm{mM}$; [1] =4 mM (2 mol\%); water $1 \mathrm{~mL}, 95^{\circ} \mathrm{C}, 18 \mathrm{~h}$.

a Determined by extraction with ethyl acetate and GC analysis. In all cases E:Z 99:1.
Table 3

Scope of the terminal alkene isomerization reaction mediated by $\mathrm{Ru}(\mathrm{II})$ catalyst $\mathbf{1}$.

Substrate Yield (\%)

Experimental conditions: [substrate] = $200 \mathrm{mM}$; [1] =4 mM (2 mol\%); [SDS] = $60 \mathrm{mM}$; water $1 \mathrm{~mL}, 95^{\circ} \mathrm{C}, 18 \mathrm{~h}$.

a Determined by extraction with ethyl acetate and GC analysis.

In order to optimize the catalytic systems, the reactions with the two best anionic surfactants were repeated in the presence of different amounts of SDS and SHS as reported in Table 2. From the data reported, it is evident that both for SDS and SHS there is a typical profile of product yield $v s$. surfactant concentration characterized by an increase of activity for concentrations above the $c$. m.c. (that is lower than $10 \mathrm{mM}$ for both surfactants) up to a maximum value followed by a decrease. This typical behavior can be attributed to an initial increase of activity due to better solubilization of both catalyst and substrate within the micelles where they can interact forming the corresponding isomerization product, followed by a decrease in catalytic activity in the presence of higher amounts of surfactant due to a dilution effect. It is worth noting that, upon optimization of the amount of surfactant employed, it was possible to obtain catalytic activities comparable to the use of a chlorinated solvent such as DCE when using SDS at a concentration of $60 \mathrm{mM}$ or using SHS at a concentration of $100 \mathrm{mM}$.

To extend the catalytic protocol and investigate the scope of the reaction, we tested catalyst $\mathbf{1}$ in the micellar medium using a series of terminal alkenes as reported in Table 3. Simple terminal alkenes like 1-octene and 1-dodecene did not react under the optimized experimental conditions. Conversely, when investigating allylbenzene derivatives endowed with methoxy substituents (Table 3 ) moderate yields were observed but the selectivity for the E isomer was in all cases almost complete as with allylbenzene. The substrates reported in Table 3 are all examples of important starting materials for the fragrance industry [33] like estragole (entry 1), 3,4-dimethoxyallylbenzene (entry 2), safrole (entry 3 ) and eugenol (entry 4).

Attempts to recycle the Ru catalyst were carried out as in Table 2 entry 2 on allylbenzene with SDS extracting the product of the reaction with ethyl acetate and adding fresh substrate to the aqueous micellar phase. Unfortunately the second run of the reaction led to the formation of only $12 \%$ of isomerized internal alkene. ${ }^{1} \mathrm{H}$ and ${ }^{31} \mathrm{P}$ NMR experiments carried out at the end of the first reaction clearly demonstrated the partial decomposition of the original complex during the reaction. On the other hand, the reaction on allylbenzene with SDS could be scaled up testing the catalytic system on $4 \mathrm{mmol}$ substrate, observing yield of $39 \%$ and $\mathrm{E}$ : $\mathrm{Z}$ ratio of $98: 2$, thus demonstrating the reliability of the catalytic method developed.

\section{Conclusion}

In conclusion, herein we reported a simple and efficient alkene isomerization method based on 2 mol\% of catalyst 1 operating in 
water in the presence of anionic surfactants that showed comparable activity with respect to the use of traditional chlorinated organic solvents. The key feature of the catalytic system is the micellar medium obtained by simple addition of commercially available SDS or SHS that favor the close contact between the apolar alkene substrate with the cationic catalyst that is likely to be positioned close to the surface of the anionic micelles. The optimized catalytic system was applied to a series of allylbenzenes that are precursors to fragrances showing excellent E-isomer selectivity and overall good performance with respect to the use of organic solvents. The latter was retained even when the reaction was scaled up to substrate gram size.

\section{Acknowledgements}

The authors thank Università Ca' Foscari Venezia and MIUR for support. Prof. Albertin from Università Ca' Foscari Venezia is gratefully acknowledged for providing samples of complex $\mathbf{1}$.

\section{Appendix A. Supplementary data}

Supplementary data associated with this article can be found, in the online version, at http://dx.doi.org/10.1016/j.ica.2016.06.004.

\section{References}

[1] (a) P.T. Anastas, Aldrichimica Acta 48 (2015) 3-4;

(b) S.K. Ritter, Aldrichimica Acta 48 (2015) 5-6;

(c) D.J.C. Constable, Aldrichimica Acta 48 (2015) 7;

(d) J.C. Warner, Aldrichimica Acta 48 (2015) 29.

[2] P.T. Anastas, J.C. Warner, Green Chemistry: Theory and Practice, Oxford University Press, New York, 1998.

[3] (a) T. Welton, Green Chem. 13 (2011) 225; (b) P.G. Jessop, Green Chem. 13 (2011) 1391

[4] R.A. Sheldon, Green Chem. 9 (2007) 1273.

[5] R.K. Henderson, C. Jiménez-Gonzàlez, D.J.C. Constable, S.R. Alston, G.G.A. Inglis G. Fisher, J. Sherwood, S.P. Binks, A.D. Curzons, Green Chem. 13 (2011) 854.

[6] (a) D. Prat, J. Hayler, A. Wells, Green Chem. 16 (2014) 4546;

(b) C. Capello, U. Fischer, K. Hungerbuhler, Green Chem. 9 (2007) 927-934;

(c) J.H. Clark, S.T. Tavener, Org. Process Res. Dev. 11 (2007) 149-155.

[7] H.C. Hailes, Org. Process Res. Dev. 11 (2007) 114.

[8] (a) U.M. Lindström, Chem. Rev. 102 (2002) 2751;

(b) S. Otto, J.B.F.N. Engberts, Org. Biomol. Chem. 1 (2003) 2809;

(c) S. Kobayashi, K. Manabe, Acc. Chem. Res. 35 (2002) 209;

(d) D. Sinou, C. Rabeyrin, C. Nguefack, Adv. Synth. Catal. 345 (2004) 357;

(e) T. Dwars, E. Paetzold, G. Oehme, Angew. Chem. Int. Ed. 44 (2005) 7174.
[9] U.M. Lindström, Organic Reactions in Water, Blackwell Publ, Hoboken, 2007.

[10] S. Liu, J. Xiao, J. Mol. Catal. A: Chem. 270 (2007) 1. and references therein.

[11] S. Narayan, J. Muldoon, M.G. Finn, V.V. Fokin, H.C. Kolb, K.B. Sharpless, Angew. Chem. Int. Ed. 21 (2005) 3275.

[12] K.H. Shaughnessy, Chem. Rev. 109 (2009) 643.

[13] (a) U.M. Lindström, Angew. Chem. Int. Ed. 45 (2006) 548-551;

(b) K. Holmberg, Eur. J. Org. Chem. (2007) 731;

(c) S. Taşcioğlu, Tetrahedron 52 (1996) 11113-11152.

[14] (a) A. Cavarzan, G. Bianchini, P. Sgarbossa, L. Lefort, S. Gladiali, A. Scarso, G. Strukul, Chem. Eur. J. 15 (2009) 7930-7939;

(b) M. Colladon, A. Scarso, G. Strukul, Adv. Synth. Catal. 349 (2007) 797-801; (c) A. Scarso, G. Strukul, Adv. Synth. Catal. 347 (2005) 1227-1234.

[15] F. Gallou, N.A. Isley, A. Ganic, U. Onken, M. Parmentier, Green Chem. 18 (2016) 14-19.

[16] G. La Sorella, G. Strukul, A. Scarso, Green Chem. 17 (2015) 644-683.

[17] F. Trentin, A.M. Chapman, A. Scarso, P. Sgarbossa, R. Michelin, G. Strukul, D.F Wass, Adv. Synth. Catal. 354 (2012) 1095-1104.

[18] M. Gottardo, A. Scarso, S. Paganelli, G. Strukul, Adv. Synth. Catal. 352 (2010) $2251-2262$.

[19] M.D. Mbaye, B. Demerseman, J.-L. Renaud, L. Toupet, C. Bruneau, Angew. Chem. Int. Ed. 45 (2003) 5066-5068.

[20] D.F. Schreiber, Y. Ortin, H. Müller-Bunz, A.D. Phillips, Organometallics 30 (2011) 5381-5395.

[21] Y. Yamamoto, T. Arakawa, R. Ogawa, K. Itoh, J. Am. Chem. Soc. 125 (2003) $12143-12160$.

[22] W. Baratta, W.A. Herrmann, R.M. Kratzer, P. Rigo, Organometallics 19 (2000) 3664-3669.

[23] (a) D. Bingham, D.A. Webster, P.B. Wells, J. Chem. Soc., Dalton Trans. (1974) 1514-1518;

(b) D. Bingham, D.A. Webster, P.B. Wells, J. Chem. Soc., Dalton Trans. (1974) 1519-1520.

[24] S. Manzini, D.J. Nelson, S.P. Nolan, ChemCatChem 5 (2013) 2848-2851.

[25] A. Cavarzan, A. Scarso, G. Strukul, Green Chem. 12 (2010) 790-794.

[26] A. Scarso, M. Colladon, P. Sgarbossa, C. Santo, R.A. Michelin, G. Strukul, Organometallics 29 (2010) 1487-1497. and references therein.

[27] S. Perdriau, M.-C. Chang, E. Otten, H.J. Heeres, J.G. de Vries, Chem. Eur. J. 20 (2014) 15434-15442.

[28] D.D. Perrin, W.L.F. Armarego, Purification of Laboratory Chemicals, third ed., Pergamon Press, Oxford, 1988.

[29] W.C. Still, M. Khan, A. Mitra, J. Org. Chem. 43 (1978) 2923.

[30] B.C. Boren, S. Narayan, L.K. Rasmussen, L. Zhang, H. Zhao, Z. Li, G. Jia, V.V. Fokin, J. Am. Chem. Soc. 130 (2008) 8923-8930.

[31] The concentration of the different surfactants (100 mM) was chosen comparable to that of the organic substrates and above the c.m.c. values for all surfactants. TPGS-750-M is commercially available as a $2 \mathrm{w} / \mathrm{w} \%$ solution in water and this solution was used directly as solvent.

[32] S. Manzini, J.A. Fernandez-Salas, S.P. Nolan, Acc. Chem. Res. 47 (2014) 30893101.

[33] (a) K. Bauer, D. Garbe, H. Surburg, Common Fragrance and Flavour Materials, fourth ed., Wiley, New York, 2001, pp. 171-226;

(b) P. Kraft, K.A.D. Swift, Current Topics in Flavour and Frangrance Research, 2008. VHCA, Zurich, and Wiley-VCH, Weinheim, Germany. 